\title{
Adding attenuation corrected images in myocardial perfusion imaging reduces the need for a rest study
}

\author{
Elin Trägårdh*, Sven Valind and Lars Edenbrandt
}

\begin{abstract}
Background: The American Society of Nuclear Cardiology and the Society of Nuclear Medicine conclude that incorporation of attenuation corrected (AC) images in myocardial perfusion scintigraphy (MPS) will improve diagnostic accuracy. The aim was to investigate the value of adding AC stress-only images for the decision whether a rest study is necessary or not.

Methods: 1,261 patients admitted to ${ }^{99 m} \mathrm{mc}$ MPS were studied. The stress studies were interpreted by two physicians who judged each study as "no rest study necessary" or "rest study necessary", by evaluating NC stress-only and NC+ AC stress-only images. When there was disagreement between the two physicians, a third physician evaluated the studies. Thus, agreement between 2 out of 3 physicians was evaluated.

Results: The physicians assessed 214 more NC + AC images than NC images as "no rest study necessary" (17\% of the study population). The number of no-rest-study-required was significantly higher for NC+ AC studies compared to NC studies (859 vs 645 cases $(p<0.0001$ ). In the final report according to clinical routine, ischemia or infarction was reported in 23 patients, assessed as "no rest study necessary" (22 NC + AC cases; 8 NC cases), (no statistically significant difference). In 11 of these, the final report stated "suspected/possible ischemia or infarction in a small area".
\end{abstract}

Conclusions: Adding AC stress-only images to NC stress-only images reduce the number of unnecessary rest studies substantially.

Keywords: Tc99m MPS, Ischemic cardiac disease, Attenuation correction, Stress-only studies

\section{Background}

Stress myocardial perfusion scintigraphy (MPS) is widely regarded as a clinically useful non-invasive imaging modality for diagnosing patients with suspected coronary artery disease. The diagnostic accuracy is high, and risk stratification has been well validated [1-3]. However, Compton scatter and depth-dependent reduction of spatial resolution degrade MPS image quality and decrease test accuracy. In addition, localized softtissue attenuation by the breasts, lateral chest wall, and abdomen may create artefacts that mimic true perfusion abnormalities and decrease test specificity $[4,5]$.

Several studies have reported an increase in the diagnostic accuracy (through higher specificity) for the detection

\footnotetext{
* Correspondence: elin.tragardh@med.lu.se

Clinical Physiology and Nuclear Medicine Unit, Skåne University Hospital, Lund University, Entrance 44, 20505 Malmö, Sweden
}

of coronary artery disease when MPS is attenuation corrected (AC) [6-12]. The American Society of Nuclear Cardiology and the Society of Nuclear Medicine conclude in their joint position statement from 2004 [6] that incorporation of AC in addition to ECG gating with MPS images will improve image quality, interpretive certainty, and diagnostic accuracy. These combined results are anticipated to have a substantial impact on improving the effectiveness of care and lowering health care costs.

One of the problems with attenuation is that it reduces laboratory efficiency by requiring comparison of stress and rest image sets to distinguish perfusion abnormalities from attenuation artefacts. If a stress study is considered completely normal, there is no need for a rest study, thus increasing laboratory efficiency and reducing the radiation dose to the patient. Heller et al. [13] investigated the clinical value of attenuation correction in

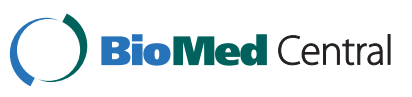


stress-only MPS and found that attenuation corrected images significantly increased the ability to interpret studies as definitely normal or abnormal and reduced the need for rest imaging.

The aim of the present study was to investigate the value of adding AC stress-only images for the decision whether a rest study is necessary or not.

\section{Methods}

\section{Study population}

All patients admitted to Tc-99m MPS at the Department of Clinical Physiology and Nuclear Medicine, Skåne University Hospital, Malmö, Sweden in 2007 were included. In total, 1283 patients were considered. Of these, 22 patients were excluded due to missing MPS data files. The study complies with the Declaration of Helsinki and was approved by the local research ethics committee at Lund University.

\section{Stress-only assessment (Evaluations between NC only and $\mathrm{NC}+\mathrm{AC}$ )}

All stress studies were interpreted by two experienced physicians who judged each study as "no rest study necessary" or "rest study necessary". When there was disagreement between the physicians, a third physician evaluated the studies. Thus, agreement between 2 out of 3 physicians was evaluated. The physicians evaluated two sets of images for each patient: NC images only, and both NC and AC images. The studies were blinded so that the evaluation for $\mathrm{NC}$ images only was not known when evaluating both $\mathrm{NC}$ and $\mathrm{AC}$ images. Stress and gated images were available for this interpretation, but not clinical information or electrocardiogram findings. The EXINI heart ${ }^{\mathrm{TM}}$ software package (EXINI Diagnostics $A B$, Lund, Sweden) was used to aid the interpretation.

\section{Clinical final report}

The final reports according to clinical routine were compared to the results from the stress-only assessment described above. All cases with infarction or ischemia present or probably present were categorized as requiring a rest study, whereas all other cases were categorized not requiring a rest study. Rest (NC and $\mathrm{AC})$, stress (NC and $\mathrm{AC}$ ), gated images, clinical information, and electrocardiogram findings were available for this interpretation, which was performed according to clinical routine by the physician in charge of the study, not knowing that the patient was included in a study. In clinical routine in our department, the physician in charge evaluates the stress images, and decides whether a rest study is necessary or not. In the study population used in this study, $44 \%$ of the studies were stress-only studies. The EXINI heart ${ }^{\mathrm{TM}}$ software package was used for the visual interpretation.

\section{Radionuclide imaging}

The MPS studies were performed using a 2-day gated stress/non-gated rest Tc-99m-tetrofosmin protocol, starting with injection of $600 \mathrm{MBq}$ Tc-99m-tetrofosmin at stress. Patients were stressed using either maximal exercise on an ergometer or pharmacological test with adenosine. The exercise was continued for at least $1 \mathrm{~min}$ after the injection of the tracer and the adenosine infusion at least $2 \mathrm{~min}$ after the injection of the tracer. Normal findings at stress were not followed by a rest study. Not definitely normal stress studies were followed by a rest study with injection of $600 \mathrm{MBq}$ Tc-99m-tetrofosmin. The need for a rest study was determined by the physician in charge of the study according to clinical routine.

Stress and rest acquisition began about $60 \mathrm{~min}$ after the end of the injection of Tc-99m-tetrofosmin. Images were obtained according to established clinical protocols, using SPECT over $180^{\circ}$ elliptical, autocontour rotations from the $45^{\circ}$ right anterior oblique position, with a dual-head gamma camera, e.cam (Siemens AG Medical Solutions, Erlangen, Germany). Patients were imaged in the supine position. Low energy high-resolution collimator and a zoom factor of 1.0 were used. We obtained 64 (32 views per camera) projections in a $128 \times 128$ matrix, with an acquisition time of $25 \mathrm{~s}$ per projection. Stress images were gated to the electrocardiogram using 8 frames per cardiac cycle. No automatic motion-correction program was applied; instead the acquisition was repeated if motion was detected. If motion was apparent on the repeated examination as well, a motion-correction program was used. Tomographic reconstruction and calculation of short and long axis slice images were performed using e.soft (Siemens AG Medical Solutions, Erlangen, Germany). NC images were reconstructed with filtered back-projection. A 2D Butterworth prereconstruction filter was used with critical frequency of 0.45 , order 5 . AC images were reconstructed with an iterative algorithm, 6 iterations [14] where a ramp filter was applied on the error projection prior to backprojection. A Butterworth filter with a cut-off frequency of 0.40 , order 5 , was applied for regularization. Attenuation maps were generated from simultaneous transmission measurement using a Gd-153 multipleline source (Siemens AG Medical Solutions, Erlangen, Germany) [15].

\section{Statistical analysis}

The McNemar test was used to analyze the differences in classification of patients between the $\mathrm{NC}$ only group and the $\mathrm{NC}+\mathrm{AC}$ images group. The level of statistical significance was set at 0.05 . Analyses were carried out using Analyse-it ${ }^{\circledR}$ for Microsoft Excel (Analyse-it Software Ltd, Leeds, UK). 


\section{Results}

The number of no-rest-study-required cases was significantly higher using the $\mathrm{NC}+\mathrm{AC}$ studies compared to the NC studies $(859$ vs 645 cases $(\mathrm{p}<0.0001)$. In 634 cases $(50 \%)$ the evaluations for both $\mathrm{NC}$ and $\mathrm{NC}+\mathrm{AC}$ stress images were no-rest-study-required and in 391 cases $(31 \%)$ that a rest study was required. In 11 cases (1\%), the physicians did not want a rest study when evaluating NC images, but wanted a rest study when evaluating $\mathrm{NC}+\mathrm{AC}$ images. In 225 cases (18\%), the physicians thought it was necessary to perform a rest study when evaluating $\mathrm{NC}$ images, but not when evaluating $\mathrm{NC}+\mathrm{AC}$ images.

961 studies (76\%) were considered normal (i.e. no ischemia or infarction present) based on the final report according to clinical routine. In 8 of the $645(1.2 \%)$ $\mathrm{NC}$ stress images classified as no-rest-study-required, ischemia/infarction was present on the final report. The corresponding results for the $\mathrm{NC}+\mathrm{AC}$ images were 22 of $859(2.6 \%)$ and this difference was not statistically significant. Cases classified as rest-study-required were more often interpreted as ischemia/infarction in the final report for the $\mathrm{NC}+\mathrm{AC}$ images (69\%) than the NC images $(47 \%)(\mathrm{p}<0.0001)$. The numbers are shown in Table $1 \mathrm{~A}$ and $\mathrm{B}$.

\section{Patients with abnormal MPS (final report) that were missed on stress-only images}

In total, 23 patients had ischemia and/or infarction on the final reports, but were regarded as "no-rest-studyrequired" on either $\mathrm{NC}$ or $\mathrm{NC}+\mathrm{AC}$ stress image evaluation; thus would falsely have been sent home without a rest study. Of these, 1 patient was missed when evaluating $\mathrm{NC}$ images, 15 when evaluating $\mathrm{NC}+\mathrm{AC}$ images and 7 patients were missed for both evaluations. In 11 of the 23 cases, the final report stated "suspected/ possible ischemia or infarction in a small area of the left ventricle"; in 9 cases "ischemia or infarction in a small area of the left ventricle"; and in 3 cases "ischemia

Table 1 The distribution of the evaluations from NC images (A) and NC+ AC images (B)

\begin{tabular}{llrrr}
\hline & & \multicolumn{2}{c}{ Final report } & \\
\cline { 3 - 4 } & & Normal & Abnormal & \\
\hline A & & & & \\
\multirow{2}{*}{ NC only } & No rest & 637 & 8 & $\mathbf{6 4 5}$ \\
& Rest & 324 & 292 & $\mathbf{6 1 6}$ \\
& & $\mathbf{9 6 1}$ & $\mathbf{3 0 0}$ & $\mathbf{1 2 6 1}$ \\
\hline $\mathrm{B}$ & No rest & 837 & & \\
$\mathrm{AC}+\mathrm{NC}$ & Rest & 124 & 22 & $\mathbf{8 5 9}$ \\
& & $\mathbf{9 6 1}$ & 278 & $\mathbf{4 0 2}$ \\
& & & $\mathbf{3 0 0}$ & $\mathbf{1 2 6 1}$ \\
\hline
\end{tabular}

in a moderately large area of the left ventricle". Two of the patients with moderately large ischemia underwent coronary angiography within 6 months after the MPS, and both received percutaneous coronary intervention (PCI). The third patient underwent coronary angiography with PCI of the right coronary artery 4 years after the MPS. Three of the 9 patients with "ischemia/infarction in a small area" underwent coronary angiography; two without any need of PCI and one with PCI of the left ascending coronary artery and the left circumflex artery. Only 1 patient with "suspected ischemia" underwent coronary angiography, with subsequent PCI of a diagonal branch. This patient got a dissection in the left main coronary artery during the angiography.

\section{Discussion}

In the present study we investigated the accuracy for determining the need for a rest study when using $\mathrm{NC}$ images or $\mathrm{NC}+\mathrm{AC}$ images. We found that adding $\mathrm{AC}$ images were superior to using only $\mathrm{NC}$ images. When using $\mathrm{NC}+\mathrm{AC}$ compared to $\mathrm{NC}$ images, 214 more patients (17\% of the study population) could avoid a rest study. The advantages of being able to reduce the number of rest studies are substantially reduced radiation exposure, lower costs by eliminating unnecessary imaging time and radiopharmaceutical doses, and improved laboratory efficiency by freeing up camera time to study additional patients.

In this material, when using $\mathrm{NC}$ images, $1.2 \%$ of the patients would have been sent home without a rest study, when a rest study was needed according to the final report. The number for AC images was 2.6\% (no statistically significant difference). The reasons for this could be either that the final report was not always correct or that the physicians who evaluated the stress studies did not have access to the clinical information (as stated in the study limitations section) or that can be difficult to see small perfusion abnormalities on stress-only images in some cases. The number of missed certain ischemia/ infarction due to a normal interpretation on stressonly images was very low in this study (less than $1 \%$ ), but the goal is not to miss any patients with ischemia or infarction. In a study by Johansson et al. [16], trying to decide whether nuclear medicine technologists are able to determine the necessity for a rest study, $2.6 \%$ of the patients would have been sent home without a rest study, when a rest study was needed according to gold standard (ischemia or infarction on combined stress-rest interpretation). Thus, their results were similar to the ones found in the present study.

The stress-only approach has been investigated in several studies. Worsley et al. [17] demonstrated that rest images were not required if normal imaging findings had been obtained after exercise or pharmacologic 
stress. This was later confirmed by Schroeder-Tanka et al. [18] in a larger study. Heller et al. [13] found that AC applied to studies with stress-only ${ }^{99 \mathrm{~m}} \mathrm{Tc}$ MPS significantly increased the ability to interpret studies as definitely normal or abnormal and reduced the need for rest imaging. In their study, ten experienced nuclear cardiologists independently interpreted 90 stress-only MPS in a sequential fashion: MPS alone, MPS plus ECG-gated data, and AC MPS with ECG-gated data. Images were interpreted for diagnostic certainty (normal, probably normal, equivocal, probably abnormal, abnormal, and perceived need for rest imaging). Adding $\mathrm{AC}$ data increased the number of studies characterized as definitely normal or abnormal to $84 \%$ (37\% for MPS data alone) and reduced the perceived need for rest imaging from $77 \%$ for MPS data only to $43 \%$ for the addition of AC data. Heller et al., however, included far fewer patients than the present study, and only included patients with either known coronary artery disease or patients with a $5 \%$ or lower likelihood of coronary artery disease. The ten independent readers also interpreted the studies in a sequential manner. The fact that only patients with known coronary artery disease or patients with a very low likelihood of coronary artery disease in combination with the sequential interpretation could be the reason for the larger difference in the number of rest studies needed when adding AC images compared to NC images only found in their study compared to the present study.

Current guidelines also recommend the stress study to be performed first, since the rest study can be omitted if the stress study is interpreted as normal [19]. Thus a rest study should only be performed in patients with equivocal or clearly abnormal studies. Chang et al. [20] investigated whether a normal stress-only MPS confers the same prognosis as a normal MPS on the bases of evaluation of stress and rest images. They found that patients who had a normal MPS on the basis of stress imaging alone have a similar mortality rate as those who have a normal MPS on the basis of evaluation of both stress and rest images.

\section{Study limitations}

In the present study the final reports according to clinical routine was used to compare the results from the stress-only assessment by the three study physicians. This might not be the optimal since physicians with different levels of experience interpreted the studies, and because there is always inter-observer variability when interpreting studies.

The physicians who evaluated the NC and AC stress studies did not have any clinical information about the patients. It is possible that fewer patients would have been falsely regarded as "no-rest-study-required" if the clinical information was available, as it is in the true clinical setting.

A third limitation is that in clinical routine at our department, physicians already evaluate the need for a rest study after the stress study (based on NC and AC stress images, gated images and clinical information). In $44 \%$ of the cases, no rest study is performed, and "no ischemia or infarction" is stated on the final report. If any mistakes were done in the clinical assessment, the final report used in the present study could be wrong.

\section{Conclusion}

Adding AC stress-only images to NC stress-only images reduce the number of unnecessary rest studies substantially. The risk that a patient sent home without a rest study would have been diagnosed with definite infarction or ischemia using the combined stress-rest interpretation was low. 214 more patients (17\% of the study population) did not require a rest study when adding AC images. We conclude that adding AC images will improve laboratory efficiency.

\section{Competing interests}

LE is employed by and stockholder of EXINI Diagnostics.

\section{Authors' contributions}

ET participated in the design of the study, acquired and evaluated the data, performed the statistical analysis and drafted the manuscript. SV evaluated the data and helped to draft the manuscript. LE participated in the design of the study, evaluated the data and helped to draft the manuscript. All authors read and approved the final manuscript.

\section{Acknowledgement}

This study was supported by the Medical Faculty at Lund University.

Received: 26 January 2012 Accepted: 27 March 2013

Published: 1 April 2013

\section{References}

1. Hachamovitch R, Berman DS, Kiat H, Cohen I, Cabico JA, Friedman J, Diamond GA: Exercise myocardial perfusion SPECT in patients without known coronary artery disease. Circulation 1996, 93:905-914.

2. Hachamovitch R, Berman DS, Shaw $\sqcup$, Kiat H, Cohen I, Cabico JA, Friedman J, Diamond GA: Incremental prognostic value of myocardial perfusion single photon emission computed tomography for the prediction of cardiac death. Circulation 1998, 97:535-543.

3. Iskander S, Iskandrian AE: Risk assessment using single photon emission computed tomography technetium-99 m-sestamibi imaging. J Am Coll Cardiol 1998, 32:57-62.

4. DePuey EG, Garcia EV: Optimal specificity of thallium-201 SPECT through recognition of imaging artefacts. J Nucl Med 1989, 30:441-449.

5. Corbett JR, Ficaro EP: Clinical review of attenuation-corrected cardiac SPECT. J Nucl Cardiol 1999, 6:54-68.

6. Heller GV, Links J, Bateman TM, Ziffer JA, Ficaro E, Cohen MC, Hendel RC: American Society of Nuclear Cardiology and Society of Nuclear Medicine joint position statement: attenuation correction of myocardial perfusion SPECT scintigraphy. J Nucl Cardiol 2004, 11:229-230.

7. Gallowitsch HJ, Sykora J, Mikosch P, Kresnik E, Unterweger O, Molnar M, Grimm G, Lind P: Attenuation-corrected thallium-201 single-photon emission tomography using a gadolinium-153 moving line source: clinical value and the impact of attenuation correction on the extent and severity of perfusion abnormalities. Eur J Nucl Med 1998, 25:220-228.

8. Hendel RC, Merman DS, Cullom SJ, Follansbee W, Heller GV, Kiat H, Groch MW, Mahmarian JJ: Multicenter clinical trial to evaluate the efficacy of correction 
for photon attenuation and scatter in SPECT myocardial perfusion imaging. Circulation 1999, 99:2742-2749.

9. Links JM, Becker LC, Rigo P, Taillefer R, Hanelin L, Anstett F, Burckhardt D, Mixon L: Combined corrections for attenuation, depth-dependent blur, and motion in cardiac SPECT: a multicenter trial. J Nucl Cardiol 2000, 7:414-425.

10. Links JM, DePueyo EG, Taillefer R, Becker LC: Attenuation correction and gating synergistically improve the diagnostic accuracy of myocardial perfusion SPECT. J NuCl Cardiol 2002, 9:183-187.

11. Thompson RC, Heller GV, Johnson LL, Case JA, Cullom SJ, Garcia EV, Jones PG, Moutray KL, Bateman TM: Value of attenuation correction on ECG-gated SPECT myocardial perfusion imaging related to body mass index. J NuCl Cardiol 2005, 12:195-202.

12. Masood Y, Liu YH, Depuey G, Taillefer R, Araujo LI, Allen S, Delbeke D, Anstett F, Peretz A, Zito MJ, Tsatkin V, Wackers FJ: Clinical validation of SPECT attenuation correction using $x$-ray computed tomography-derived attenuation maps: multi-center clinical trial with angiographic correlation. J Nucl Cardiol 2005, 12:676-686.

13. Heller GV, Bateman TM, Johnson LL, Cullom SJ, Case JA, Galt JR, Garcia EV, Haddock K, Moutray KL, Poston C, Botvinick EH, Fish MB, Follansbee WP, Hayes S, Iskandrian AE, Mahmarian JJ, Vandecker W: Clinical value of attenuation correction in stress-only Tc-99m sestamibi SPECT imaging. J NuCl Cardiol 2004, 11:273-281.

14. Wallis JW, Miller TR: Rapidly converging iterative reconstruction algorithms in single-photon emission computed tomography. J Nucl Med 1993, 34:1793-1800

15. Hawman EG, Ray M, Xu R, Vija AH: An attenuation correction system for a dedicated small FOV, dual head, fixed- $90^{\circ}$ cardiac gamma camera using arrays of Gd-153 line sources. IEEE Nucl Science Symposium Conference Record 2006, 3:1806-1810.

16. Johansson L, Lomsky M, Gjertsson P, Sallerup-Reid M, Johansson J, Ahlin NG, Edenbrandt $L$ : Can nuclear medicine technologists assess whether a myocardial perfusion rest study is required? J Nucl Med Technol 2008, 36:181-185.

17. Worsley DF, Fung AY, Coupland DB, Rexworthy CG, Sexsmith GP, Lentle BC: Comparison of stress-only vs. stress/rest with technetium-99 m methoxyisobutylisonitrile myocardial perfusion imaging. Eur J Nucl Med 1992, 19:441-444.

18. Schroeder-Tanka JM, Tiel-van Buul MM, van der Wall EE, Roolker W, Lie Kl, van Royen EA: Should imaging at stress always be followed by imaging at rest in Tc-99m MIBI SPECT? A proposal for a selective referral and imaging strategy. Int J Card Imaging 1997, 13:323-329.

19. Hesse B, Tägil K, Cuocolo A, Anagnostopoulos C, Bardies M, Bax J, Bengel F, Busemann Sokole E, Davies G, Dondi M, Edenbrandt L, Franken P, Kjaer A, Knuuti J, Lassmann M, Ljungberg M, Marcassa C, Marie PY, McKiddie F, O'Connor M, Prvulovich E, Underwwod R, van Eck-Smit B: EANM/ESC procedural guidelines for myocardial perfusion imaging in nuclear cardiology. Eur J Nucl Med Mol Imaging 2005, 32:855-897.

20. Chang SM, Nabi F, Xu J, Raza U, Mahmarian JJ: Normal stress-only versus standard stress/rest myocardial perfusion imaging: similar patient mortality with reduced radiation exposure. J Am Coll Cardiol 2010, 55:221-230

doi:10.1186/1471-2342-13-14

Cite this article as: Trägårdh et al:: Adding attenuation corrected images in myocardial perfusion imaging reduces the need for a rest study. BMC Medical Imaging 2013 13:14.

\section{Submit your next manuscript to BioMed Central and take full advantage of:}

- Convenient online submission

- Thorough peer review

- No space constraints or color figure charges

- Immediate publication on acceptance

- Inclusion in PubMed, CAS, Scopus and Google Scholar

- Research which is freely available for redistribution 